\title{
scripted
}

Volume 15, Issue 1, August 2018

\section{Book review: Research Handbook on EU Health Law and Policy}

Tamara K. Hervey, Calum Alasdair Young and Louise E. Bishop (eds.) Cheltenham: Edward Elgar Publishing, 2017. 640 pages.

ISBN $9781785364716 . £ 175$.

Reviewed by Edward S. Dove*

$$
\text { (c) }(9)
$$

(C) 2018 Edward S. Dove

Licensed under a Creative Commons Attribution-NonCommercial-

NoDerivatives 4.0 International (CC BY-NC-ND 4.0) license

DOI: $10.2966 /$ scrip.150118.130

* Lecturer in Risk and Regulation, School of Law, University of Edinburgh 
In this new edition to Edward Elgar Publishing's "Research Handbooks in European Law" series, Tamara Hervey, Calum Young, and Louise Bishop, all of Sheffield Law School, bring together a panoply of leading EU legal scholars who unpack different aspects of EU health law and policy in 19 chapters. The editors completed this book shortly after the Brexit referendum in June 2016, and the impact of that referendum result is palpably felt at different points across these 600 pages. Foremost, it is felt in the Foreword from Martin McKee, Professor European Public Health at the London School of Hygiene \& Tropical Medicine, who writes pointedly in his opening sentence that: "No one, following the events of early 2016, can be in any doubt of the need for a book that explains important aspects of European Union policy. The United Kingdom engaged in a debate on its relationship with Europe that revealed a profound degree of ignorance of all things European" (p. xi). In many ways, then, this Research Handbook on EU Health Law and Policy can be treated as an educational tool - particularly for those in the UK - to uncover the EU's growing contributions to health law and policy, though one is doubtful how many Brexit voters will read this book or any other book in the Elgar European Law series. Indeed, this Research Handbook is not geared primarily to a UK populace ignorant "of all things European". Instead, it has a broader purpose. As the editors observe, "[w]hatever the future relationship between the $\mathrm{UK}$ and the EU, and whichever way the EU itself develops, the EU's involvement with health law and policy will continue" (p. 1). What the editors seek to do is offer, from a variety of disciplinary perspectives, including law, political science, policy studies, and sociology, 1) expert views on the current status of EU health law and policy, and 2) horizon scanning on what future directions they may take. This is a book aimed at readers interested in European health law and policy on a continental level, EU institutional level, and indeed even a global level. 
Not surprisingly in such a large edited collection, some chapters are stronger than others, and several shine with their adept analysis and clear writing. Foremost, the editors provide a brilliant and beautifully written introduction. Hervey, Young, and Bishop discern three broad themes in their book:

- "Fractured decision-making, leading to policy ineffectiveness or incoherence" (p. 6). That is, pursuing health agendas within the EU's institutional structures is "complicated by the actors and the decisionmaking processes involved" (p. 6), which are dispersed among different institutional settings.

- "The place of 'science' and 'innovation' in EU health law and policy" (p. 7). As several of the contributing authors suggest, the EU has struggled to balance effectively the (societal) desire to enable novel technological developments and protecting the interests and welfare of patients, health systems, and others.

- "The fragility and frustrated potential of EU health law and policy, and yet its remarkable durability [:] ....although EU health law and policy may be seen as long-standing, it is also seen as precarious" (p. 9). Related to the second theme, here the editors highlight concerns with constitutional asymmetry in EU law, where "the logic of the market stands in a hierarchical relationship above other logics" (p. 9), i.e. health may stand in a non-equal relationship to market-based values.

The editors suggest that one potential direction in EU health law and policy is an increased focus on human rights - which would see the protection and promotion of health as a central value of EU law and policy (pp. 10-11).

Excellent chapters include Mary Guy and Wolf Sauter's chapter (Chapter 1) on "The history and scope of EU health law and policy". Guy and Sauter 
explore the nature of EU health law and policy, query how their scope has developed within the broader context of EU law/integration, and chart their possible direction of travel. The authors divide their historical account into three periods: 1957-2002; 2002-2007; and 2007-present. As they note, the 1957 Rome Treaty contained no explicit references to health, with the exception of public health, as a justification for restrictions on free movement. The first piece of EU legislation pertaining to public health was on food safety, with a Directive on colourants in foodstuffs being adopted in 1962. From 1992 onwards, they argue that the EU witnessed a high point of integration of health into EU policies with "the scope for health rights [...] significantly expanded" (p. 29). Even in the postLisbon period, defined by "political malaise" and (a lessening) "persistent economic downturn", "the integration of health into EU policies continues" (p. 32). Looking to the future, Guy and Sauter observe two key related trends: demographic ageing and the shift towards chronic health conditions. This will lead to spiralling costs in health systems. The authors equivocate as to whether this will result mainly in cost cutting or in new and/or common solutions across the EU.

A second excellent chapter worth highlighting is Markus Frischhut and Scott L. Greer's chapter on "EU public health law and policy - communicable diseases", which opens Part IV on Public Health (and which, in my opinion, is the strongest Part of the Research Handbook). Here, Frischhut and Greer present the historic development of EU communicable disease control law and policy since the 1990s. They write with noted disappointment that the EU hitherto has been a weak actor in public health law. This is largely "because it lacks coercive capabilities such as quarantine or distributive powers such as vaccination programmes". However, they write more optimistically that with the strength of its human rights law and its "increasing role in setting norms of good practice for public health", it is "increasingly, slowly, being drawn into the debates about 
privacy, coercion and proportionality that mark communicable disease control law in most States" (p. 316). Ultimately, Frischhut and Greer paint a story of a developing network in the EU that plays a more effective role in communicable disease control. Yet political and legal challenges remain, foremost in regards to risk management and response, given that the EU "has very weak Treaty powers and Member States have deep conflicting incentives and responses" (p. 328).

Overall, this Research Handbook on EU Health Law and Policy is a welcome addition to the libraries of EU health lawyers and policymakers. A small criticism is that the editors and authors alike could have been clearer in demarcating the (albeit fluid) boundaries between law and policy. Interested readers will dip into chapters that appeal to their needs and interests, and the well-constructed bibliography and helpful glossary will appeal to keen and novice EU health law and policy scholars alike. I am pleased that despite the precarious future of the UK's relationship with the EU, the editors offer an optimistic outlook - at least insofar as the EU is concerned: "If the reasons for the EU institutions not having pursued health agendas in the past, despite formal legal competence and sufficient resources, lie in the political preferences of governments of powerful Member States, an EU without the UK may offer altered possibilities" (p. 11). Indeed. And a contrario, one can read into this quote a foreboding sense of concern about the UK's diminished role in Europe and the world, coupled with a lingering worry over the predominance of market-based values that subordinate health values and public interests. 